\title{
Effects of different analgesia regimens on early post-operative cognitive dysfunction in elderly patients undergoing radical resection of cervical carcinoma
}

\author{
WEI YAN ${ }^{1}$, HUAJIE MAO ${ }^{2}$ and PING QIU ${ }^{1}$ \\ ${ }^{1}$ Department of Anesthesiology, Huzhou Maternity and Child Health Care Hospital, Huzhou, Zhejiang 313000; \\ ${ }^{2}$ Department of Anesthesiology, Ningbo Yinzhou No. 2 Hospital, Ningbo, Zhejiang 315040, P.R. China
}

Received May 13, 2019; Accepted June 21, 2019

DOI: $10.3892 / \mathrm{etm} .2019 .7702$

\begin{abstract}
This study was designed to compare the effects of epidural and intravenous analgesia on early post-operative cognitive dysfunction (POCD) in elderly patients undergoing radical resection of cervical cancer. For this purpose, 74 patients aged 60-78 years [body mass index (BMI), $18-25 \mathrm{~kg} / \mathrm{m}^{2}$; American Society of Anesthesiologists (ASA) classification score of I-III) undergoing radical resection of cervical cancer were divided into the epidural group (group E) and parenteral group (group P) groups (37 patients in each group). All patients underwent their surgical procedures under epidural anesthesia and intravenously-delivered general anesthesia. Patient-controlled analgesia (PCA) was supplied for 72 $\mathrm{h}$ after the surgery. Epidural analgesia was provided for the patients in group $\mathrm{E}$ and intravenous analgesia was provide for those in group P. General patient information was recorded and peripheral blood neutrophil counts, $\mathrm{C}$-reactive protein (CRP) levels and interleukin (IL)-6 concentrations were measured immediately prior to the surgery $\left(\mathrm{T}_{0}\right)$, and at 24,48 and $72 \mathrm{~h}$ after the procedure $\left(\mathrm{T}_{1}, \mathrm{~T}_{2}\right.$ and $\mathrm{T}_{3}$, respectively). Visual analog scale (VAS) scores were also recorded at $\mathrm{T}_{1}, \mathrm{~T}_{2}$ and $\mathrm{T}_{3}$, and the mini-mental state evaluation (MMSE) scores at $\mathrm{T}_{0}, \mathrm{~T}_{1}, \mathrm{~T}_{2}$, and $\mathrm{T}_{3}$ were calculated. Patients were diagnosed as having POCD according to their MMSE score differences between the peri-operative and post-operative values. The results revealed that the levels of CRP and IL-6 significantly increased in both groups after the surgery $\left(\mathrm{T}_{1-3}\right)$. However, the CRP and IL-6 levels in group E were significantly lower than those in group $\mathrm{P}$ at all time points examined $(\mathrm{P}<0.05)$. The VAS scores in group $\mathrm{E}$ at $\mathrm{T}_{1}, \mathrm{~T}_{2}$ and $\mathrm{T}_{3}$ were significantly lower than those in group $\mathrm{P}(\mathrm{P}<0.05)$. Finally, the incidence of $\mathrm{POCD}$ in group
\end{abstract}

Correspondence to: Professor Ping Qiu, Department of Anesthesiology, Huzhou Maternity and Child Health Care Hospital, No. 2 East Street, Wuxing, Huzhou, Zhejiang 313000, P.R. China E-mail: qiupingtracy@163.com

Key words: epidural analgesia, intravenous analgesia, cervical cancer, post-operative cognitive dysfunction
E was significantly lower than that in group $\mathrm{P}(\mathrm{P}<0.05)$. On the whole, the post-operative epidural analgesia reduced the systemic inflammatory response, the perceived pain, and the incidence of POCD in patients undergoing radical resection of cervical cancer, when compared with the effects of intravenous analgesia.

\section{Introduction}

Post-operative cognitive dysfunction (POCD) is a common post-operative complication affecting the central nervous system in elderly patients. It leads to increased medical costs for patients, impairs their recovery after surgery, and can even increase mortality (1). Risk factors for POCD include pain and being of the female sex $(2,3)$, and the incidence of POCD is higher in elderly patients undergoing cardiovascular and orthopedic surgical procedures (4). Unfortunately, studies on POCD incidence and severity in post-menopausal elderly women are limited, with some attention paid to this population cohort in the context of breast cancer treatment $(5,6)$. Thus, the present study was designed to compare the effects of epidural and intravenous analgesia on early POCD in elderly women undergoing the radical resection of cervical cancer.

\section{Patients and methods}

Patient information. The Ethics Committee of Huzhou Maternity and Child Health Care Hospital approved this retrospective medical records review (Ethics committee no. 201818), and all patients signed informed consent forms. In total, 74 patients were enrolled [aged 60-78 years; body mass index (BMI), $18-25 \mathrm{~kg} / \mathrm{m}^{2}$; American Society of Anesthesiologists (ASA) classification score of I-III] from January to December, 2018, who were undergoing radical resection of cervical cancer in our hospital. The pre-operative mini-mental state evaluation (MMSE) scores $(7,8)$ of all the patients were $>24$. Patients with abnormal coagulation functions, local infection of epidural puncture sites, and severe heart, brain, liver, kidney, or other organ diseases, those with mental illness, central nervous system diseases, and a history of chronic pain, or of allergies, and abuse, or dependence to local anesthetics were excluded. Patient-controlled analgesia (PCA) was supplied for $72 \mathrm{~h}$ after 
the surgery. A random number table was used to divide the patients into 2 groups as follows: Those receiving epidural analgesia after the surgery (group E) and those receiving those receiving parenteral analgesia after the surgery (group P), with 37 patients in each group. No statistically significant differences were observed in terms of the general information between the patients in both groups ( $\mathrm{P}>0.05$; Table I).

Anesthetic methods. All patients fasted for $6 \mathrm{~h}$, and were deprived of water beginning $2 \mathrm{~h}$ prior to the surgery. After entering the operating room, the patients inhaled oxygen by masks, and their electrocardiogram (ECG), heart rate (HR), blood pressure (BP), blood oxygen saturation $\left(\mathrm{SPO}_{2}\right)$ and bispectral index (BIS) were monitored. Crystalloid infusions were provided at a rate of $6 \mathrm{ml} / \mathrm{kg} / \mathrm{h}$ and the surgeons completed the procedures under epidural combined with intravenous general anesthesia. For the epidural anesthesia method, patients were asked to adopt a left lateral position, and the anesthesiologist performed an epidural puncture between the L2-3 vertebral bodies and inserted a catheter $3-4 \mathrm{~cm}$ to the head side. Subsequently, the anesthesiologist infused $3 \mathrm{ml}$ of $1 \%$ lidocaine and checked for local anesthetic poisoning or total spinal anesthesia; in the absence of these phenomena, $10 \mathrm{ml} 0.75 \%$ ropivacaine were additionally infused. For the intravenous general anesthesia method, the anesthesiologist used midazolam $(0.05 \mathrm{mg} / \mathrm{kg})$, sufentanyl $(0.5 \mathrm{mg} / \mathrm{kg})$, etomidate $(0.3 \mathrm{mg} / \mathrm{kg})$, and cisatracurium $(0.15 \mathrm{mg} / \mathrm{kg})$ in sequence for induction. The mechanical ventilation after the tracheal intubation then commenced with a tidal volume of $6-8 \mathrm{ml} / \mathrm{kg}$, a respiratory frequency of 12 times/min, and breath-to-breath ratio of $1: 2$. Propofol $2-10 \mathrm{mg} / \mathrm{kg} / \mathrm{h}$ and remifentanil $0.1-0.3 \mu \mathrm{g} / \mathrm{kg} / \mathrm{h}$ were infused intravenously, and cisatracurium was added intermittently during the procedure. The end-tidal $\mathrm{CO}_{2}\left(\mathrm{PetCO}_{2}\right)$ was maintained at $35-45 \mathrm{mmHg}$ and the bispectral index (BIS) value at 40-60. If the mean arterial pressure of a patient decreased $>20 \%$ of the pre-operative value, deoxyepinephrine (50-100 $\mu \mathrm{g})$ was administered intravenously. The anesthesiologist discontinued all anesthetics $10 \mathrm{~min}$ prior to the end of the procedure, and ondansetron $(8 \mathrm{mg})$ was administered intravenously. All patients were observed in the recovery room following extubation. PCA analgesia pumps were installed half an hour prior to the end of the surgery and until $72 \mathrm{~h}$ thereafter. The patients in group E were connected to an epidural analgesia pump $(0.125 \%$ ropivacaine; background dose, $8 \mathrm{ml} / \mathrm{h}$; PCA dose, $2 \mathrm{ml} /$ time; at 20 -min intervals). The patients in group $\mathrm{P}$ were connected to an intravenous analgesia pump (sufentanyl $1.5 \mu \mathrm{g} / \mathrm{kg}$; background dose, $2 \mathrm{ml} / \mathrm{h}$; PCA dose, $2 \mathrm{ml} /$ time; at 20-min intervals). Diazepam (5 mg) was prescribed for patients in any group with visual analog scale (VAS) scores $>4$ points (9). Briefly, patients were asked to rate their pain level by placing a single mark along a $10 \mathrm{~cm}$ line, with the left end $(0 \mathrm{~cm})$ representing 'no pain' and the right end $(10 \mathrm{~cm})$ representing 'worst pain'. The distance from the mark to the left end in centimeters was taken as the VAS score.

Observation index. The background information was recorded of all the patients. The peripheral blood neutrophil levels, C-reactive protein (CRP) levels and interleukin (IL)-6 concentrations were measured before the surgery $\left(\mathrm{T}_{0}\right)$, and at 24,48 and $72 \mathrm{~h}$ after the surgery $\left(\mathrm{T}_{1}, \mathrm{~T}_{2}\right.$, and $\mathrm{T}_{3}$, respectively) in all patients. In addition, the $\mathrm{T}_{1}, \mathrm{~T}_{2}$, and $\mathrm{T}_{3}$ VAS scores, and $\mathrm{T}_{0}$, $\mathrm{T}_{1}, \mathrm{~T}_{2}, \mathrm{~T}_{3}$ MMSE scores (10) (27-30 points, normal; cognitive impairment, $<24$ points; POCD, post-operative score 2 points lower than pre-operative score) were calculated.

Statistical analysis. All data using SPSS 13.0 statistical software (Leadtools). Measurement data are expressed as the means \pm standard deviation (means $\pm \mathrm{SD}$ ), and count data were compared using Chi-squared tests. For comparisons between 2 groups, the independent sample t-test was used. All P-values $<0.05$ were considered to indicate statistically significant differences.

\section{Results}

In total, 3 patients were found with epidural catheter slippage in group $\mathrm{E}$, and 1 patient with analgesic pump failure in group P; thus, their data were excluded from the analysis. No significant intraoperative differences were found between the 2 groups ( $\mathrm{P}>0.05$; Table II).

In addition, the peripheral blood neutrophil counts were similar between the 2 groups at each time point. The levels of CRP and IL-6 increased significantly in both groups after the surgery $\left(\mathrm{T}_{1-3}\right)$. The levels of CRP and IL-6 in group E were significantly lower than those in group $\mathrm{P}$ at each time point $(\mathrm{P}<0.05$; Table III).

The VAS scores in group $\mathrm{E}$ at $\mathrm{T}_{1}, \mathrm{~T}_{2}$ and $\mathrm{T}_{3}$ were significantly lower than those in group $\mathrm{P}$ at the same time points $(\mathrm{P}<0.05$; Table IV). In addition, no significant differences were observed in the pre-operative MMSE scores between the patients in the 2 groups. However, the post-operative MMSE scores at each time point in group $\mathrm{E}$ were significantly higher than those in group $\mathrm{P}(\mathrm{P}<0.05)$. The incidence of POCD in group $\mathrm{E}$ was significantly lower than that in group $\mathrm{P}(\mathrm{P}<0.05$; Table V).

\section{Discussion}

POCD is a common postoperative complication and its risk factors include the education level, the presence of hypertension, diabetes mellitus and other comorbidities (11). Age is an independent risk factor for POCD (12), and the incidence of POCD in elderly patients is higher than that in younger patients. Estrogen exerts protective effects on cognitive function (13). The incidence of POCD in menopausal elderly women increases with the gradual estrogen secretion decreases. In our clinical practice, the incidence of POCD is approximately $18.57 \%$ in elderly patients undergoing the radical resection of cervical cancer, and this percentage is in agreement with the published incidence of 17 to $43 \%$ in elderly patients following non-cardiac surgery (9).

The central cholinergic system plays an important role regulating cognitive function (14). Atropine (an anticholinergic drug) can increase the concentration of acetylcholine, influencing the central cholinergic system (15). In order to avoid the effects of cholinergic blockers on POCD, we avoided using cholinergic drugs throughout the peri-operative period. Phenylephrine increases the cerebral blood flow and oxygen consumption, causing an imbalance in brain metabolism that can lead to POCD (16). In this study, no significant differences 
Table I. Comparison of general information between the 2 groups of patients.

\begin{tabular}{lcccccc}
\hline Group & Age (years) & BMI $\left(\mathrm{kg} / \mathrm{m}^{2}\right)$ & ASA (I/II/III) & Years of education & Diabetes n (\%) & Hypertension n (\%) \\
\hline Group E & $67.5 \pm 2.8$ & $22.3 \pm 2.3$ & $5 / 30 / 2$ & $6.1 \pm 1.0$ & $5(13.5)$ & $11(29.7)$ \\
Group P & $68.4 \pm 3.2$ & $22.8 \pm 2.6$ & $4 / 30 / 3$ & $6.2 \pm 1.1$ & $4(10.8)$ & $13(35.1)$ \\
\hline
\end{tabular}

No significant differences were found between the 2 groups. BMI, body mass index; ASA, American Society of Anesthesiologists (ASA) classification score.

Table II. Comparison of intraoperative conditions between the 2 groups.

\begin{tabular}{lcccccc}
\hline Group & Case no. & $\begin{array}{c}\text { Operative } \\
\text { time }(\mathrm{min})\end{array}$ & $\begin{array}{c}\text { Intraoperative } \\
\text { bleeding volume }(\mathrm{ml})\end{array}$ & $\begin{array}{c}\text { Remifentanil } \\
\text { dosage }(\mathrm{mg})\end{array}$ & $\begin{array}{c}\text { Oxygenated } \\
\text { adrenaline dosage }(\mu \mathrm{g})\end{array}$ & $\begin{array}{c}\text { Remedy } \\
\text { analgesia rate n }(\%)\end{array}$ \\
\hline $\mathrm{E}$ & 34 & $145.6 \pm 13.5$ & $240.8 \pm 26.3$ & $1.4 \pm 0.2$ & $20.3 \pm 7.1$ & $2(5.9 \%)$ \\
$\mathrm{P}$ & 36 & $151.3 \pm 14.8$ & $235.9 \pm 30.5$ & $1.5 \pm 0.4$ & $25.1 \pm 8.2$ & $3(8.3 \%)$ \\
\hline
\end{tabular}

No significant differences were found between the 2 groups.

Table III. Comparison of neutrophil counts, and the levels of CRP and IL-6 between the 2 groups at different time points .

\begin{tabular}{|c|c|c|c|c|c|c|}
\hline \multirow[b]{2}{*}{ Time point } & \multicolumn{3}{|c|}{ Group E } & \multicolumn{3}{|c|}{ Group P } \\
\hline & Neutrophils (\%) & CRP (mg/l) & IL-6 (pg/ml) & Neutrophils (\%) & $\mathrm{CRP}(\mathrm{mg} / \mathrm{l})$ & IL-6 (pg/ml) \\
\hline T0 & $69.7 \pm 3.9$ & $55.1 \pm 8.9$ & $27.1 \pm 6.9$ & $70.8 \pm 2.5$ & $53.6 \pm 8.1$ & $29.7 \pm 8.0$ \\
\hline $\mathrm{T} 1$ & $70.2 \pm 3.3$ & $94.4 \pm 7.4^{\mathrm{a}}$ & $95.2 \pm 6.8^{\mathrm{a}}$ & $69.9 \pm 2.8$ & $99.6 \pm 9.7$ & $102.5 \pm 9.1$ \\
\hline $\mathrm{T} 2$ & $70.0 \pm 3.5$ & $98.3 \pm 9.9^{\mathrm{a}}$ & $64.3 \pm 5.5^{\mathrm{a}}$ & $69.2 \pm 2.3$ & $111.0 \pm 11.2$ & $86.8 \pm 6.7$ \\
\hline $\mathrm{T} 3$ & $67.1 \pm 2.4$ & $66.5 \pm 5.7^{\mathrm{a}}$ & $32.6 \pm 8.9^{a}$ & $67.7 \pm 2.1$ & $78.3 \pm 8.6$ & $57.2 \pm 7.3$ \\
\hline
\end{tabular}

${ }^{\mathrm{a}} \mathrm{P}<0.05$, compared with group P. CRP, C-reactive protein; IL-6, interleukin 6.

Table IV. Comparison of the mean VAS scores between the 2 groups at different time points.

\begin{tabular}{lccc}
\hline Group & $\mathrm{T} 1$ & $\mathrm{~T} 2$ & $\mathrm{~T} 3$ \\
\hline $\mathrm{E}$ & $3.1 \pm 0.9$ & $3.0 \pm 0.7^{\mathrm{a}}$ & $2.8 \pm 0.5^{\mathrm{a}}$ \\
$\mathrm{P}$ & $3.8 \pm 1.5$ & $3.5 \pm 1.0$ & $3.1 \pm 0.6$ \\
\hline
\end{tabular}

${ }^{\mathrm{a}} \mathrm{P}<0.05$, compared with group P. VAS, visual analog scale.

Table V. Comparison of the MMSE scores and the POCD incidence between the 2 groups at different time points.

\begin{tabular}{lcccrr}
\hline Group & T0 & T1 & T2 & T3 & POCD incidence \\
\hline E & $28.8 \pm 2.0$ & $25.3 \pm 2.7^{\mathrm{a}}$ & $25.2 \pm 2.8^{\mathrm{a}}$ & $26.7 \pm 2.1^{\mathrm{a}}$ & $3(8.1 \%)^{\mathrm{a}}$ \\
$\mathrm{P}$ & $28.5 \pm 2.2$ & $23.7 \pm 2.9$ & $23.3 \pm 2.2$ & $25.5 \pm 2.3$ & $10(27.8 \%)$ \\
\hline
\end{tabular}

${ }^{\mathrm{a}} \mathrm{P}<0.05$, compared with group P. MMSE, mini-mental state evaluation; POCD, post-operative cognitive dysfunction.

were found in pre-operative complications, intraoperative medications, or surgical conditions between the 2 groups.
It has been demonstrated that inflammation in the central system is the initiating event in the pathogenesis of POCD (17). 
The pathological state of the cancer in patients may promote central nervous system inflammation (18), and the release of inflammatory mediators during the surgery may further affect the function of the central nervous system, leading to POCD. Thus, reducing the post-operative systemic inflammatory response may help to reduce the incidence of POCD. IL-6 and CRP are systemic inflammatory response markers, and IL-6 can also be used as a reliable indicator for assessing the presence of POCD (19). From our observations, the surgeries caused increases in the levels of CRP and IL-6 in all patients; however, the levels of CRP and IL-6 in the patients in group E were significantly lower than those in the patients in group $\mathrm{P}$, suggesting that epidural analgesia is better for controlling inflammation than intravenous analgesia.

Pain is a post-operative risk factor for $\operatorname{POCD}(2,20)$. Effective post-operative analgesia does not only relieve pain and improve comfort, but also reduces the release of catecholamines and other stress hormones during the post-operative period (21), and these factors should reduce the incidence of POCD. In this study, the mean post-operative VAS scores of group E were lower than those of group P at each time point, suggesting that epidural analgesia is more effective. Studies have concluded that the VAS score is an independent risk factor for POCD (22), and they have also shown that opioids affect post-operative cognitive function in patients, whether administered intravenously or through the epidural route $(23,24)$. Therefore, in this study, although both the MMSE scores of the $\mathrm{E}$ and $\mathrm{P}$ groups were significantly lower after surgery (the MMSE score was lowest at $48 \mathrm{~h}$ post-surgery), the mean MMSE scores in group $\mathrm{E}$ were higher than those in group $\mathrm{P}$ at each time point, and the incidence of POCD in the patients in group $\mathrm{E}$ was also lower than that of the patients in group $\mathrm{P}$.

In conclusion, the findings of this study suggest that the use of post-operative epidural analgesia can reduce the systemic inflammatory response, as it provides an effective an analgesic effect and reduces the incidence of POCD in patients undergoing radical resection of cervical cancer tumors. Therefore, the use of post-operative epidural analgesia is worthy of further investigation and clinical promotion.

\section{Acknowledgements}

Not applicable.

\section{Funding}

No funding was received.

\section{Availability of data and materials}

The datasets used and/or analyzed during the current study are available from the corresponding author upon reasonable request.

\section{Authors' contributions}

WY conceived and designed the study; WY and HM carried out experiments; WY and PQ analyzed the data and wrote the manuscript; WY, HM, and PQ reviewed and edited the manuscript. All authors read and approved the final manuscript.

\section{Ethics approval and consent to participate}

The Ethics Committee of Huzhou Maternity and Child Health Care Hospital approved this retrospective medical records review (Ethics committee no. 201818). All of the patients signed patient consents prior to enrollment in the study.

\section{Patient consent for publication}

Not applicable.

\section{Competing interests}

The authors declare that they have no competing interests.

\section{References}

1. Borges J, Moreira J, Moreira A, Santos A and Abelha FJ: Impact of postoperative cognitive decline in quality of life: A prospective study. Rev Bras Anestesiol 67: 362-369, 2017 (In Portuguese).

2. Borozdina A, Qeva E, Cinicola M and Bilotta F: Perioperative cognitive evaluation. Curr Opin Anaesthesiol 31: 756-761, 2018.

3. Iqbal J, Ghaffar A, Shahbaz A and Abid AR: Stroke after coronary artery bypass surgery with and without cardiopulmonary bypass. J Ayub Med Coll Abbottabad 26: 123-128, 2014.

4. Scott JE, Mathias JL and Kneebone AC: Postoperative cognitive dysfunction after total joint arthroplasty in the elderly: A meta-analysis. J Arthroplasty 29: 261-267.e1, 2014.

5. Sato C, Sekiguchi A, Kawai M, Kotozaki Y, Nouchi R, Tada H, Takeuchi H, Ishida T, Taki Y, Kawashima R, et al: Postoperative Structural Brain Changes and Cognitive Dysfunction in Patients with Breast Cancer. PLoS One 10: e0140655, 2015.

6. Sekiguchi A, Sato C, Matsudaira I, Kotozaki Y, Nouchi R, Takeuchi H, Kawai M, Tada H, Ishida T, Taki Y, et al: Postoperative hormonal therapy prevents recovery of neurological damage after surgery in patients with breast cancer. Sci Rep 6: 34671, 2016.

7. Psychiatry \& Behavioral Health Learning Network: Mini-Mental State Examination (MMSE). https://www.psychcongress. $\mathrm{com} / \mathrm{mini}$-mental-state-examination-mmse.

8. Wong H, Larre P and Ghawché F: Polynesian adaptation of the mini-mental state examination. Rev Neurol (Paris) 171: 359-366, 2015. (In French).

9. Delgado DA, Lambert BS, Boutris N, McCulloch PC, Robbins AB, Moreno MR and Harris JD: Validation of Digital Visual Analog Scale Pain Scoring With a Traditional Paper-based Visual Analog Scale in Adults. J Am Acad Orthop Surg Glob Res Rev 2: e088, 2018.

10. Zhou ZJ, Tang J, Li WH and Tao WD: Preoperative intravenous flurbiprofen reduces postoperative pain and inflammatory cytokines in elderly patients after hip arthroplasty. Exp Ther Med 17: 354-358, 2019.

11. Evered L, Silbert B, Scott DA, Ames D, Maruff P and Blennow K: Cerebrospinal Fluid Biomarker for Alzheimer Disease Predicts Postoperative Cognitive Dysfunction. Anesthesiology 124: 353-361, 2016.

12. Strøm C, Rasmussen LS and Sieber FE: Should general anaesthesia be avoided in the elderly? Anaesthesia 69 (Suppl 1): 35-44, 2014.

13. Ong W-Y, Farooqui T, Koh H-L, Farooqui AA and Ling E-A: Protective effects of ginseng on neurological disorders. Front Aging Neurosci 7: 129, 2015.

14. Knox D and Keller SM: Cholinergic neuronal lesions in the medial septum and vertical limb of the diagonal bands of Broca induce contextual fear memory generalization and impair acquisition of fear extinction. Hippocampus 26: 718-726, 2016.

15. Terry AV Jr: Role of the central cholinergic system in the therapeutics of schizophrenia. Curr Neuropharmacol 6: 286-292, 2008.

16. Schwartz AE, Minanov O, Stone JG, Adams DC, Sandhu AA, Pearson ME, Kwiatkowski P, Young WL and Michler RE: Phenylephrine increases cerebral blood flow during low-flow hypothermic cardiopulmonary bypass in baboons. Anesthesiology 85: 380-384, 1996. 
17. Hawkins RB, Raymond SL, Stortz JA, Horiguchi H, Brakenridge SC, Gardner A, Efron PA, Bihorac A, Segal M, Moore FA, et al: Chronic Critical Illness and the Persistent Inflammation, Immunosuppression, and Catabolism Syndrome. Front Immunol 9: 1511, 2018

18. Chen L, Deng H, Cui H, Fang J, Zuo Z, Deng J, Li Y, Wang X and Zhao L: Inflammatory responses and inflammation-associated diseases in organs. Oncotarget 9: 7204-7218, 2017.

19. Peng L, Xu L and Ouyang W: Role of peripheral inflammatory markers in postoperative cognitive dysfunction (POCD): A meta-analysis. PLoS One 8: e79624, 2013.

20. Ye H, Chen R, Lian X, Huang J, Mao Y, Lu R, Ai S, Ma W, Lin J, Yang $\mathrm{H}$, et al: Risk factors associated with postoperative pain and discomfort in oculoplastic surgery with general anesthesia: A prospective study. J Pain Res 11: 407-415, 2018.
21. Webster LR, Brennan MJ, Kwong LM, Levandowski R and Gudin JA: Opioid abuse-deterrent strategies: Role of clinicians in acute pain management. Postgrad Med 128: 76-84, 2016.

22. Neeman E, Zmora O and Ben-Eliyahu S: A new approach to reducing postsurgical cancer recurrence: Perioperative targeting of catecholamines and prostaglandins. Clin Cancer Res 18: 4895-4902, 2012.

23. Zywiel MG, Prabhu A, Perruccio AV and Gandhi R: The influence of anesthesia and pain management on cognitive dysfunction after joint arthroplasty: A systematic review. Clin Orthop Relat Res 472: 1453-1466, 2014.

24. Fong HK, Sands LP and Leung JM: The role of postoperative analgesia in delirium and cognitive decline in elderly patients: A systematic review. Anesth Analg 102: 1255-1266, 2006. 